\title{
Mulheres encarceradas e seus filhos: exercício da perversão no mundo capitalista?
}

\author{
Ilka Franco Ferrari*1
}

O texto aborda questões sobre a perversão feminina, percorrendo modos de vida de mulheres encarceradas com seus filhos, no Centro de Referência à Gestante Privada de Liberdade, em Minas Gerais, a partir de informações pontuais advindas de pesquisa que ali se realizou. A psicanálise orienta a trilha e, na convicção lacaniana sobre a inexistência da perversão feminina, chega-se ao insuportável funcionamento de ser mãe em tempo integral, para essas gestoras dos corpos das crianças.

Palavras-chave: Mulheres encarceradas, mães, filhos, perversão

*1 Pontifícia Universidade Católica de Minas - PUC-Minas (Belo Horizonte, $\mathrm{MG}, \mathrm{Br})$. 
Nossa realidade social está marcada pela organização discursiva conhecida como discurso do capitalista, cuja essência é rechaçar a modalidade do impossível, característica da castração. Nela há a condição proletariada de todos os humanos, conforme avisa Lacan (1970/2003a), colocando-os em falta de gozar, em sistema que considera poder suprir a falta, digamos, em moldes perversos. Nessa falta de impossibilidade observa-se que tudo o que está no mundo se torna mercadoria, e na oferta de objetos mais de gozar o sistema faz-se instrumento do gozo do Outro, deixando cada qual na solidão de sua própria causa.

As mulheres, nesse enfrentamento, convivem com a condição desejante sem maiores coerções, pois estruturalmente podem viver a disjunção entre procriação, sexo e amor. Daí, não raro se ouve que elas se exercitam na perversão. E, quando se trata de mulheres encarceradas, mais favorecedora é essa forma de pensar.

\section{Mulheres encarceradas: laço com o crime, desenlace familiar}

Esse subtítulo é nome da primeira pesquisa realizada no "Centro de Referência à Gestante Privada de Liberdade", localizado em Vespasiano, Minas Gerais, e implantado em 2009, pelo governo do Estado. Ela recebeu apoio financeiro do CNPq, Fapemig e FIP PUC-Minas, e contou com pesquisadores colaboradores da Universidade de Pernambuco, Universidade de São João Del Rei, Universidade de Barcelona e Universidade de Antioquia, da Colômbia. Realizou-se com o consentimento da instituição na qual o estudo aconteceu, bem como com o aceite da Superintendência de Atendimento ao Preso, e aprovação do Comitê de Ética da PUC-Minas. 
A partir de informações pontuais dessa pesquisa se extrai os argumentos deste texto que, ademais, laçam posições para nova investigação, já em curso, intitulada "Laços sociais de crianças após o cárcere", também com apoio governamental (Fapemig), mas com nova equipe.

A invenção desse Centro pode ser vista como uma forma de resposta ao mal-estar de nossa cultura hipermoderna, resposta à crise capitalista estabelecida em seu projeto de "produzir um sujeito novo, sem legado histórico nem herança simbólica". Sujeito tributário de nada que não seja colaborar com a vontade acéfala caracterizada por não considerar consequência alguma, conforme afirma Alemán (2009). Seu estabelecimento se justificou em considerações sobre humanização do sistema prisional, resgate de cidadania e promoção de responsabilidades, por meio da garantia de convívio de mãe e filho em instalações sem grades, a partir dos dois últimos meses de gravidez até o primeiro ano de vida da criança. Excepcionalmente acolhe mulheres em pós-parto ou grávidas antes do sétimo mês, quando o caso exige cuidados, e pode haver permanência maior que um ano, decorrente de impasses na destinação da guarda da criança, pelo juiz, se a mãe segue presa em outro cárcere. O projeto dessa unidade prisional, considerada modelo para a América Latina, sustenta a ideia do contato pele a pele e do aleitamento materno, como essenciais para a criança no primeiro ano de vida. Isso, no sentido de que eles fortalecem o vínculo psicoafetivo que assegurará bons contatos, duradouros a ponto de resistir até a saída da mãe do presídio. Relatório detalhado dessa pesquisa foi entregue às autoridades implicadas no assunto, e está disponível na Biblioteca da PUC-Minas (Ferrari et al., 2014).

Uma constatação que surpreendeu aos pesquisadores e, possivelmente às autoridades implicadas, é que entre as 23 das 56 detentas que foram voluntariamente ouvidas na época, a maioria dizia da insuportável posição de ser mãe 24 horas por dia, mesmo naquela prisão considerada modelo. Preferiam estar em cárcere fechado, sem a criança. Não as suportavam "grudadas em seus corpos todo o tempo", como uma delas expressou, sem ter com quem dividir os cuidados. Tê-las ali era mais castigo que prêmio. Em prisão, quando não se faz amiga para contar com ajuda, informavam, todas as responsabilidades de cuidados recaem sobre a mãe, desde o momento de sua volta do hospital, não importando se parto normal ou cesárea. Entre elas havia aquelas que nitidamente deliravam, e uma delas, ainda grávida, confessou que não queria nem saber, estava disposta a deixar o filho no próprio hospital; outra, que se apresentou como deprimida e com transtorno bipolar, olhos lagrimejantes, contou como sofria escutando o choro das 
crianças todos os dias e noites. Entre todas, somente uma detenta dizia que, apesar de concordar com as críticas feitas à instituição, queria estar com a criança, seu primeiro filho, e sofria imaginando o dia em que se separariam.

O método utilizado para obtenção de informações foi o da conversação, forma de pesquisar orientada pelo método clínico (Miller et al., 2003), dispositivo da psicanálise clínica que se estende a outros espaços em procedimento grupal, sem perder a dimensão do sujeito. Seu piloti é a existência de associação livre que é coletivizada, pois o dizer de um ressoa no outro, colocando-o também a trabalho e promovendo pontos para análise. Os participantes debatem sobre o tema proposto, sem a injunção de um saber prévio conduzindo o trabalho e considerando a dimensão do sujeito, ainda que em grupo. Nesse caso, os participantes debateram sobre temas propostos a partir de uma conversação inicial, chamada "Conversação diagnóstica" (Santiago, 2011), pois dela foram retirados os pontos cruciais das três conversações que seguiram.

\section{Local de manifestações da perversão feminina?}

Nessa instituição ocorria o que os pesquisadores passaram a denominar de "presença contínua": pouca estimulação exterior que pudesse funcionar como terceiro, promovendo a separação necessária entre mãe e criança. Presença contínua, em modalidade de vínculo que se pode definir como convivência obrigatória, própria dos presídios. Nesse caso, há ainda a exigência de que a mulher seja mãe em tempo integral, e mesmo aquelas que têm parceiros não têm direito a visita íntima. Funcionamento dessa ordem faz com que ocorra o pensamento de que ali a perversão feminina encontra terreno fértil: algumas dessas mulheres encontraram seu objeto/filho, têm certeza de como obter gratificação, estão focadas no desejo do Outro, não sabendo gozar já que o gozo não é para elas, mas para o Outro.

Somando-se a isso, nos espaços onde a psicanálise ecoa, a partir de Freud e Lacan há o dizer de que a perversão feminina se realiza na maternidade: o filho lhe restitui o falo, na equivalência falo/filho, ou, em linguagem mais atual, criança/objeto $a$, tal como ocorre com o fetichista e o objeto fetiche.

$\mathrm{Na}$ trilha lacaniana, no entanto, encontra-se a perversão como inexistente na mulher, ainda que no Seminário VI (1958-1959) Lacan afirme a semelhança entre a fórmula do inconsciente da mulher e do perverso. Semelhança, nada mais que isso, pois a falta fálica a faz suportar ser objeto, fetiche do desejo masculino, enquanto para perverso não se trata de suportar, 
pois por gosto está a serviço do gozo do Outro. Em "Subversão do sujeito" (Lacan, 1966/1998a), por exemplo, aparece o homem como o sexo débil em relação à perversão, como se ela estivesse ligada diretamente à constituição de seu desejo. E, no Seminário XIII (1965-1966), Lacan assegura que as mulheres nada entendem da perversão. Se elas chegam a ser o objeto $a$ do homem, isso não é de seu gosto. Isso, não negando a fantasia e possibilidade de gozo perverso.

A tese mais clássica sobre essa evidência de sua não estruturação, na mulher, é exatamente o fato de que elas têm outra perversão: a maternidade (Soler, 2004). Mas nem por isso são estruturalmente perversas. É possível pensar que a perversão na mulher só acontece por ela se articular à fantasia masculina de gozo, mas, se ela ai se articula, não se articula toda e, como não toda, está excluída da perversão. Há aquelas que se posicionam do outro lado, ou seja, não sendo não todas, lugar em que se colocam as histéricas, funcionando no campo do gozo castrado do mestre, em uma perversão que se pode chamar de generalizada, não estrutural. Nem por isso são perversas e até são exímias em questionar a perversão generalizada do homem. Nas palavras de Soler (2004), "que se trate de histéricas buscando o saber sobre o mais de gozar do mestre ou de "uma mulher não toda conectada a um gozo sem objeto', não há nada menos perverso que as mulheres" (p. 223).

É no texto "Televisão" (1973/2003b) que Lacan afirma que a mulher se presta à perversão do homem, à sua fantasia, e por isso não coloca limite nas concessões que estão prontas a lhe fazer: de seu corpo, de seus bens e de sua alma. Todas as mulheres, que compareceram às conversações realizadas no Centro de Referência, ali estavam nessas condições. Evidenciava-se a maioria sintomaticamente envolvida com o tráfico de drogas de seus parceiros e com o real da existência de um filho, já que por mais que se conte com o nascimento de um filho, esse acontecimento conta sempre com a surpresa, com aquilo que foge ao programado.

Em "Nota sobre a criança" (1969/2003c), lá está Lacan dizendo, e a clínica evidencia, que a mãe tem um gozo que homem algum tem, e que não se trata do gozo feminino. Refere-se ao fato de ela ver aparecer, no real, o objeto de sua existência, nesse caso, a criança que lhe presentifica o impossível de dizer, pois ela the apresenta um espelho real do objeto que o sujeito mãe foi e, como tal, impossível de alcançar. A mãe lacaniana, ressalta-se, vale por seu desejo (não por seu amor, como em Freud), mas principalmente porque tem um acesso especial ao real, com tudo o que isso comporta. Não é sem sentido, então, que em "Observações sobre o relatório de Daniel 


\section{ARTIGOS}

Lagache" Lacan (1966/1998b) critica a ideia de unidade fusional primária, simbiose entre mãe e criança, muito presente em sua época, e destaca a maternidade legitimada pelo discurso, pela linguagem. Para ele, a mãe tem efeitos de inconsciente, como se lê no Seminário 20 (1972-1973/1985), referindo-se a seus efeitos de palavra.

Não se deve ignorar que a mãe sobre a qual Lacan fala, entretanto, desde o berço é a gestora do corpo da criança. Ele até dizia que a criança está a seu serviço sexual, ao seu uso erótico e/ou narcisista, sem esquecer que Freud, em sua "Sobre o narcisismo: uma introdução" (1914/1969), já havia abordado o uso narcísico da criança. Tal criança está, portanto, a serviço da ocorrência da língua privada desse primeiro corpo a corpo, com palavras deixando suas marcas. A regulação de seu corpo passa pelos imperativos maternos, por sua voz ou pela voz de seus substitutos, e até os leigos são capazes de reconhecer esse fato. A mãe lacaniana, portanto, não é um semblante (diferentemente do pai); está claramente implicada na reprodução real dos corpos, e tudo faz crer que a expressão instinto, a ela atribuída e usada em "Diretrizes para um congresso sobre sexualidade feminina" (1966/1998c), destina-se a dizer dessa sua peculiaridade de não semblante. Por isso mesmo é importante separar-se dela. Sabemos que Lacan advertiu que podemos ir além do pai com a condição de nos servirmos dele, mas seu leitor não encontra o mesmo aviso em relação à mãe, talvez porque dela se deve também ir além, para não mais servi-la, como escreve Soler (2004).

Em psicanálise os estudiosos se preocupam com a mãe nada dedicada à criança, bem como com aquela inteiramente a ela dedicada, sem que seu desejo por um homem ou outras coisas da vida a afaste. Isso porque, não é difícil concluir por meio da clínica, quanto mais a mãe se torna exclusiva na mediação do discurso, mais poderosos são seus mandatos e o uso erótico e/ou narcisista da criança. Mas, reflitamos, há também a possibilidade de o uso erótico se separar do narcisista, ponto em que a criança pode cair em um silêncio insondável, ainda que existam os cuidados de seu corpo, próprio das crianças esquizofrênicas.

\section{A insuportável regulação dos laços}

No Centro de Referência, com seus princípios e objetivos cheios de boas intenções, as prisioneiras e as crianças não raro eram abandonadas, até 
mesmo por familiares mais íntimos. É frequente a inexistência oficial de pais nos registros e, quando existem, não raro abandonam à sorte a mãe e a criança. E, não há como ignorar, na falta de um desejo de mulher, encontra-se o risco da alienação da criança à mãe. $\mathrm{O}$ ambiente favoreceu, portanto, pensar em uma criança à disposição da cilada do desejo materno e seus mandatos, inclusive na possibilidade de sua queda no vazio insondável anteriormente citado. Uma funcionária, também em uma das três conversações destinadas a elas, em tom de curiosa perplexidade, constatou que ali as crianças se desenvolviam fisicamente bem, mas demoravam muito para falar... Parecia que as mães ou colegas que ajudavam nos cuidados andavam com elas todos os dias, por todos os lados, nos braços ou enganchadas na cintura, sem lhes dirigirem palavras... Cadê a perversão feminina?

Nas conversações as falas diziam de mães angustiadas deparando-se com a angústia de castração que pode ser mobilizada pelo filho: angústia de perdê-los para a morte, já que a prisão não contava com pediatra naquela ocasião, e havia muitos problemas nas instalações, inadequadas para crianças pequenas; angústia pela separação que necessariamente adviria, temida e desejada; angústia de ser agente dos limites do gozo para as crianças em seus cuidados; do não saber o que fazer com aquela coisinha viva, inicialmente muito próxima da vida e do gozo não marcado pelo significante.

Se a mãe primeiramente está no lugar do Outro da demanda de amor, demanda impossível por ser incondicional, aí ela será, necessariamente, um objeto decepcionante, pois introduz a demanda condicional: à condição disso, se faz aquilo. A partir da mãe, surge a primeira decepção, e a maioria conhecia e sofria por isso, queixando-se dos serviços da prisão-modelo que não atendia à obrigatoriedade de cuidados com que se comprometeu: a instituição não podia falhar! Bastavam suas próprias falhas. Todos sofreriam na hora da separação, melhor a criança não ficar ali por muito tempo! E, nesse caminho, a maioria exigia seus direitos de decidir se queriam ou não estar ali com seus filhos, direito de ser escutada denunciando, entre outros fatos, a demora judicial sobre a guarda das crianças que poderiam estar melhor em outros lugares, especialmente com suas avós maternas.

Não foi possível detalhar os motivos de tal escolha pela avó materna, mas elas pareciam estar no lugar de alguém suposto saber acerca dos comportamentos elementares necessários à maternidade, ainda que sofressem críticas. Ademais, todas indicadas possuíam condições financeiras, ainda que mínimas, para dar conta da vida de mais um vivente. E, tal situação, sem dúvida, favorece reflexão acerca do fato de que a criança, 


\section{ARTIGOS}

mais que outros objetos, diga ao mundo sobre a tese lacaniana do parceiro sintoma, parceiro do gozo, sintoma como acontecimento de corpo. Pode-se pensar que, por isso mesmo, o modelo do "para todas", proposto pela instituição, se vê esburacado por sujeitos que, aos trancos e barrancos, cada qual a seu estilo, desconstruíam o conjunto de regras ordenador da instituição.

O estudo de dois documentos do Centro de Referência favoreceu construir o perfil de todas as mulheres prisioneiras daquela ocasião: o "Prontuário jurídico", que traz informações referentes à vida penal da presidiária, a exemplo dos processos a que está respondendo, o histórico de entradas e saídas no sistema prisional, comportamento carcerário, levantamento de pena e outras; e o "Prontuário de saúde", onde há o histórico de todos os atendimentos e exames realizados pela interna, na área da saúde, incluindo a "entrevista de classificação do preso", que é feita pela psicóloga e pela assistente social, quando há a transferência para o Centro de Referência. Nele há os exames pré-natais realizados, relatório de medicamentos administrados e processo de indicação da guarda provisória do bebê, entre outras informações. Por meio do perfil se observava que realmente as avós maternas eram as mais eleitas para cuidarem dos netos.

O juiz, entretanto, é quem decide o que considera melhor para cada uma das crianças, e não havia a garantia de que a pessoa indicada pela mãe seria eleita. Houve, na ocasião, um caso em que todas as pessoas indicadas não foram aceitas, e o parente que poderia acolher a criança se recusava a fazê-lo. Enquanto isso, tal criança continuava no Centro de Referência, bem depois do tempo estabelecido para a saída, brincando basicamente com besouros e coquinhos caídos do pé, temendo estranhos, principalmente homens.

Nessa regulação de laços, proposta pelo Estado, no modelo "para todas" como se mencionou acima, é possível dizer que há a ignorância de que o nascimento de um bebê é um momento particular para uma mulher. As mulheres podem aceder ou não à maternidade, seja esse filho desejado ou não, e jamais é suficiente reafirmar que gravidez, parto e amamentação não asseguram a maternidade, o desejo de ser mãe e laços afetivos que suportem os avatares da vida em comum, mesmo que legisladores os queiram, e ainda que o ambiente busque atender bem os cidadãos. Nada na natureza das coisas diz como, e o que é ser mãe, muito menos diz das paixões geradas no nascimento de um filho, ou do desamparo que pode surgir diante da presença real de uma criança. Nada na natureza diz do cárcere privado, subjetivo, a que cada qual ali está sujeito. 
Os matizes do mundo exterior permaneciam solapados pela rotina institucional, e até a televisão introduzia a inércia, repetindo o mesmo programa infantil, Galinha Pintadinha, conforme queixou a maioria e foi confirmado nas conversações com as funcionárias. A saída das crianças somente acontecia em casos de busca de recursos médicos para alguma doença. Nesse processo, como se observa, há ensurdecimento para o fato de que a abertura para o exterior, isso sim, enriquece a relação mãe e filho.

Tal abertura libera o sufoco da repetição e excesso de presença, e em qualquer circunstância familiar considera-se a importância do mundo exterior e seus objetos, promovendo novos laços, novas circunstâncias de vida. Para a criança, ele permite aprendizagem diferente da curricular, pois favorece a construção do seu aparelho psíquico e funcionamento civilizatório.

É inegável que viver em civilização supõe compartilhar modos de distribuição dos meios e maneiras de gozar, o que leva à historicidade de toda $\mathrm{e}$ qualquer sociedade precisando de dispositivos para delimitar o que é proibido. É impossível desconsiderar a vocação humana pelo ato infrator, por aquilo que é censurado. Por isso mesmo, como enfatiza Ambertín (2006), é importante a existência de um sistema simbólico-normativo construído a partir do campo da lei que funda e respalda toda sociedade, visando dar conta da realidade concreta do cotidiano, ainda mais porque a travessia do crime é feita no campo do proibido. Formas de castigo consequentemente surgem e, pesarosamente, nem todas considerando a responsabilidade do sujeito por seus atos.

As formas de castigar dizem do modo como se pensa a subjetividade de uma época e Lacan (1966/1998d) é feliz ao dizer que o castigo é "uma característica essencial da ideia do homem que prevalece numa dada sociedade" (p. 139). O Centro de Referência está aí, como exemplo paradigmático. Mas Foucault (1999), em Vigiar e punir, é outro autor que ilumina as ideias ao ponderar que prisão é pena das sociedades civilizadas, perigosa quando não útil. E, aqui vale acrescentar, ainda que ela esteja com o semblante das boas intenções.

Participantes da pesquisa e direção do Centro de Referência leram o relatório antes da publicação e possuem cópia. Autoridades governamentais receberam o retorno do trabalho realizado. Os pesquisadores desejam que reflitam sobre as informações. 


\section{ARTIGOS}

\section{Referências}

Alemán, J. (2009). Para una izquierda lacaniana... Buenos Aires: Grama ediciones.

Ambertín, M G. (2006). Ley, prohibición y culpabilidad. In M. G. Ambertín (Org.), Culpa, responsabilidad y castigo en el discurso jurídico e psicoanalítico (pp. 37-56). Buenos Aires: Letra Viva.

Ferrari, I. F. (2014). Mulheres encarceradas: laços com o crime, desenlace familiar. Belo Horizonte-MG. Relatório de pesquisa para o CNPq, Fapemig e FIP/ PUCMinas.

Foucault, M. (1999). Vigiar e punir: nascimento da prisão. Petrópolis-RJ: Vozes.

Freud, S. (1969). Sobre o narcisismo: uma introdução. In Edição Standard Brasileira de Obras Psicológicas Completas de Sigmund Freud (Vol. XIV, pp. 89-122). Rio de Janeiro: Imago (Original publicado em 1914).

Lacan, J. (1958-1959). O seminário. Livro 6. O desejo e sua interpretação (inédito).

Lacan, J. (1965/1966). O seminário 13. O objeto da psicanálise (inédito).

Lacan, J. (1985). O seminário. Livro 20. Mais, ainda. Rio de Janeiro: Jorge Zahar. (Original publicado em 1972-1973).

Lacan, J. (1998a). Subversão do sujeito e dialética do desejo no inconsciente freudiano. In Escritos (pp. 807-842). Rio de Janeiro: Jorge Zahar. (Original publicado em 1966).

Lacan, J. (1998b). Observações sobre o relatório de Daniel Lagache: "Psicanálise e estrutura da psicanálise". In Escritos (pp. 653-691). Rio de Janeiro: Jorge Zahar. (Original publicado em 1966).

Lacan, J. (1998c). Diretrizes para um congresso sobre a sexualidade feminina. In Escritos (pp. 734-748). Rio de Janeiro: Jorge Zahar. (Original publicado em 1966).

Lacan, J. (1998d). Introdução teórica às funções da psicanálise em criminologia. In Escritos (pp.127-151). Rio de Janeiro: Jorge Zahar. (Original publicado em 1966).

Lacan, J. (2003a). Radiofonia. In Outros Escritos (pp. 400-447). Rio de Janeiro: Jorge Zahar. (Original publicado em 1970).

Lacan, J. (2003b). Televisão. In Outros Escritos. Rio de Janeiro: Jorge Zahar. (Original publicado em 1973).

Lacan, J. (2003c). Nota sobre a criança. In Outros Escritos (pp. 369-370). Rio de Janeiro: Jorge Zahar. (Original publicado em 1969).

Miller, J. A. et al. (2003). La pareja y el amor: conversaciones clínicas con Jacques-Alain Miller en Barcelona. Buenos Aires: Paidós.

Santiago, A. L. (2011). Entre a saúde mental e a educação: abordagem clínica e Rev. Latinoam. Psicopat. Fund., São Paulo, 19(4), 678-690, dez. 2016 
pedagógica de sintomas na escola nomeados por dificuldades de aprendizagem e distúrbios de comportamento. In A. L. Santiago, R. H. F. Campos (Orgs.), Educação de crianças e jovens na contemporaneidade: pesquisas sobre sintomas na escola e subjetividade. Belo Horizonte: Ed. PUC-Minas.

Soler, C. (2004). Declinaciones de la angustia - Curso 2000/2001. Barcelona: Librería Xeroi.

\section{Resumos}

(Imprisoned women and their children: An exercise of perversion in the capitalist world?)

The text addresses questions regarding female perversion, retracing the ways of life of women imprisoned with their children in the Center of Reference to the Pregnant Woman Deprived of Freedom, in Minas Gerais, Brazil, based on information from research that was locally carried out. The content is guided by psychoanalysis and, from the lacanian conviction regarding the absence of female perversion, we are led to the unbearable condition - for these childbearers - of being full-time mothers.

Key words: Imprisoned women, mothers, children, perversion

(Les femmes détenues et leurs enfants: exercice de la perversion dans le monde capitaliste?)

L'article présent aborde les questions sur la perversion féminine, tout en parcourant les modes de vie de femmes détenues avec leurs enfants au Centre de Référence à la Femme Enceinte Privée de Liberté à Minas Gerais, à partir d'informations spécifiques provenant d'une recherche effectuée sur le terrain. La psychanalyse oriente le parcours et, basé sur la conviction lacanienne de l'inexistence de la perversion féminine, on arrive à l'insupportable fonctionnement d'être mère à plein temps, en ce qui concerne ces gestionnaires de corps des enfants.

Mots clés: Femmes détenues, mères, enfants, perversion

(Mujeres encarceladas y sus hijos: ¿ejercicio de la perversión en el mundo capitalista?)

En el texto se abordan cuestiones sobre la perversión femenina, recorriendo estilos de vida de mujeres encarceladas con sus hijos en el Centro de Referencia a la Gestante Privada de la Libertad, en Minas Gerais, desde información puntual proveniente de la investigación que se llevó a cabo allí. El psicoanálisis orienta el camino y, en la convicción lacaniana sobre la inexistencia de la perversión femenina, se llega al 


\section{ARTIGOS}

insoportable funcionamiento de ser madre de tiempo completo, para esas gestoras de los cuerpos de los niños.

Palavras clave: Mujeres encarceladas, madres, hijos, perversión

(Inhaftierte Frauen und ihre Kinder: Ausüben der Perversion in der kapitalistischen Welt?)

Dieser Artikel untersucht Aspekte der weiblichen Perversion und analysiert dazu die Lebensweisen von Frauen, die mit ihren Kindern im Zentrum für Schwangere Insassinen in Minas Gerais inhaftiert sind. Dazu wurden spezifische Informationen benutzt, die sich aus einer dort durchgeführten Studie ergaben. Unsere Vorgehensweise stützt sich auf die Psychoanalyse und basierend auf der Überzeugung Lacans bzgl. des Fehlens der weiblichen Perversion kommt man zum Schluss, dass Vollzeit-Mutter eine unerträgliche Beschäftigung ist für die Gebärenden dieser Kinder-Körper.

Schlüsselwörter: Inhaftierte Frauen, Mütter, Kinder, Perversion

（女性冈犯以及她的子女：资本主义社会的性倒错行为?）

此篇文章将会讨论女性性倒错问题, 藉由敏纳斯吉拉斯洲女囚孕妇健康中 心所调查研究的客观信息, 分析女性囚犯和她的子女相处的生活型式。依拉康 信念, 精神分析有关于女性性倒错的心理轨迹并不存在。于照顾这些儿童的管 理员来说，担任全日制母亲角色的工作是难以承受的。

关键字: 女性囚犯, 母亲, 子女, 倒错行为

Citação/Citation: Ferrari, I. F. (2016, dezembro). Mulheres encarceradas e seus filhos: exercício da perversão no mundo capitalista? Revista Latinoamericana de Psicopatologia Fundamental, 19(4), 678-690.

Editores do artigo/Editors: Profa. Dra. Ana Maria Rudge e Profa. Dra. Sonia Leite

Recebido/Received: 9.12.2015/ 12.9.2015 Aceito/Accepted: 19.2.2016 / 2.19.2016 
Copyright: (C) 2009 Associação Universitária de Pesquisa em Psicopatologia Fundamental/ University Association for Research in Fundamental Psychopathology. Este é um artigo de livre acesso, que permite uso irrestrito, distribuição e reprodução em qualquer meio, desde que o autor e a fonte sejam citados / This is an open-access article, which permits unrestricted use, distribution, and reproduction in any medium, provided the original authors and sources are credited.

Financiamento/Funding: Pesquisa financiada pelo Conselho Nacional de Desenvolvimento Científico e Tecnológico - CNPq; Fundação de Amparo à Pesquisa de Minas Gerais - Fapemig e Fundo de Incentivo à Pesquisa - FIP PUC-Minas / The research was funded by the Conselho Nacional de Desenvolvimento Científico e Tecnológico - CNPq; Fundação de Amparo à Pesquisa de Minas Gerais - Fapemig and Fundo de Incentivo à Pesquisa - FIP PUC-Minas.

Conflito de interesses/Conflict of interest: A autora declara que não há conflito de interesses

/ The author has no conflict of interest to declare.

\section{Ilka Franco Ferrari}

Doutora em Psicologia; Programa de Pós-graduação em Psicologia da Pontifícia Universidade Católica de Minas Gerais - PUC Minas.

Rua Prof. José Renault, 526 - São Bento

30350- 342 Belo Horizonte, MG, Br

francoferrari@terra.com.br

This is an open-access article, which permits unrestricted use, distribution, and reproduction in any medium for non-commercial purposes provided the original authors and sources are credited. 